\title{
ACCIÓN AFIRMATIVA: UNA VÍA PARA REDUCIR LA DESIGUALDAD
}

Patricia Begné*

Sumario:

I. Introducción. II. Surgimiento de la Acción Afirmativa. III. Necesarias las acciones afirmativas. $I V$. La práctica de la acción afirmativa. $V$. Conclusiones.

Resumen: El término acción afirmativa se refiere a aquellas acciones positivas que reduceno eliminan prácticas discriminatorias contra sectores excluídos de la población tales como mujeres, o grupos étnicos o de cierta preferencia sexual. Se busca con ello darles un trato preferencial y utilizar mecanismos diseñados expresamente para obtener resultados. Este artículo es sobre el término acción afirmativa en México, y como políticas públicas, tales como Ley General de Igualdad para Mujeres y Hombres, trata de implementar reglas para reducir prácticas discriminatorias.

Palabras clave: Acción afirmativa, desigualdad, equidad, discriminación.

\begin{abstract}
The term affirmative action refers to those positive actions to reduce or, ideally, eliminate discriminatory practices against historically excluded sectors such as women or certain ethnic groups, sexual or racial. It then seeks to increase the representation of them, through preferential treatment for themselves and selection mechanisms designed expressly and positively to these purposes. This article is about the term "affirmative action" in Mexico, and how the public policies, such as Ley General de Igualdad para Mujeres y Hombres" tries to implement rules to reduce discriminatory practices.
\end{abstract}

Keywords:Affirmative action, inequality, equity, discrimination

\section{INTRODUCCIÓN}

Agradezco la invitación que la División de Derecho, Política y Gobierno, formula a los profesores. Para quienes hemos dedicado la vida entera a la docencia, investigación y extensión en la Universidad de Guanajuato, es un privilegio arribar, colaborar en esta nueva época de la Revista de Investigaciones, que mantiene la tradición de la Revista, que desde 1981, editara el entonces Departamento de Investigaciones Jurídicas de la Facultad de Derecho.

\footnotetext{
* Profesora en la División de Derecho, Política y Gobierno de la Universidad de Guanajuato y actualmente Procuradora de los derechos académicos de la misma Universidad.
} 
Decidí escribir sobre un tema de la mayor importancia para mí, por la sencilla razón de que como estudiante de la entonces Escuela de Derecho, éramos pocas las mujeres en cada grupo y fuimos objeto de discriminación por algunos de los profesores de esa época. Mi especial situación de mujer casada y con hijos pequeños, no era común, por lo que ostentaba el status de peculiar. Logré obtener el primer lugar durante toda la licenciatura y culminar con el "Premio al Mejor Estudiante de México" que otorgaba un organismo en la ciudad de México y consistía en recibir un documento de manos del Presidente de la República en una ceremonia en el Palacio de Bellas Artes.

En el séptimo semestre decidí empezar a combinar la teoría y práctica y me presenté en un despacho de conocido abogado de la localidad y a adentrarme en el litigio. Sobra decir que en esa época, ser mujer en el litigio no era fácil. Cuando recibo invitación para integrarme a la Escuela de Derecho, de inmediato acepté y es momento que continúo laborando en la Universidad de Guanajuato. Con la anterior introducción, inicio el tema hablando de equidad.

Equidad es una palabra que hace poco ingresó al vocabulario democrático, pero que tiene orígenes muy antiguos. Viene del latín aequus, que quiere decir igual, y su acepción está vinculada totalmente al ámbito de la justicia: equidad es dar a cada persona lo que corresponda; esto es, la cualidad por la que ninguna de las partes es favorecida de manera injusta en perjuicio de otra.

Esta cualidad explica por qué, en un momento de reconocimiento de las diferencias, la equidad se ha convertido en un objetivo a alcanzar.

La equidad subyace en la lógica que movió a un conjunto de países a pasar de las políticas de igualdad de trato a las políticas de igualdad de oportunidades y, de ahí a promover las acciones afirmativas. Como en México no ha habido un debate público al respecto y como hasta 1996 se ha carecido de un organismo y programa gubernamental sobre la mujer, a continuación se ofrece un breve panorama de las razones y mecanismos más frecuentes con que se ponen en marcha los programas de igualdad entre los sexos.

\section{SURGIMIENTO DE LA ACCIÓN AFIRMATIVA}

En 1955, en Alabama Estados Unidos se produjo un incidente en que una mujer negra se negó a ceder su asiento en un autobús de servicio público a un hombre blanco. Como consecuencia de la discriminación de que 
eran objeto los negros, éstos se organizaron para protestar y nombraron a Martin Luther King como su líder. ${ }^{1}$

Eso fue el surgimiento de la Acción Afirmativa que concluyó años después de luchas en la propuesta del Acta de Derechos Civiles que impulsó el Presidente Kennedy en 1963. Ese mismo año, Kennedy reconoció la necesidad de hacer de la acción afirmativa una política de estado que permitiera al país integrarse como una auténtica comunidad democrática. El contenido de esta Acta era facilitar los puestos de trabajo a todas las personas con independencia de su color, y a suprimir cualquier división o distinción entre personas negras y blancas. $^{2}$

Desde hace más de 30 años, y bajo los auspicios de la Organización de las Naciones Unidas, ONU, los gobiernos de casi todos los países diseñaron programas para alcanzar la igualdad de derechos y obligaciones entre mujeres y hombres. La primera Conferencia Mundial de la Mujer, auspiciada por la ONU (México, 1975) representó, dentro del contexto del resurgimiento feminista de los años setenta, una llamada de atención internacional sobre la situación generalizada de subordinación y discriminación de las mujeres. La mayoría de los países que suscribió la Declaración de esa conferencia, promulgó leyes o hizo reformas a sus constituciones para garantizar la igualdad de derechos y obligaciones entre mujeres y hombres. ${ }^{3}$

A partir de ahí, los gobiernos de muchas naciones establecieron una serie de programas, medidas, reglamentaciones y convenios relativos a la necesidad de alcanzar la igualdad entre los hombres y las mujeres. Así, muchos Estados pensaron que con la implantación de ciertas medidas jurídicas que reglamentaran la igualdad social se lograría disminuir la desigualdad entre mujeres y hombres.

A principios y mediados de los años ochenta, aquellos países revisaron el funcionamiento de las leyes de igualdad entre los sexos promulgadas desde 1975. Entonces, tuvieron que reconocer que una sociedad des-

\footnotetext{
${ }^{1}$ Rodríguez Zepeda Jesús. Un marco teórico para la discriminación. http: ceidas. org/ documentos. Pag. 33, consultado en internet, el 30 de junio de 2009

2 Idem. Páginas 67 y 69
}

Recomiendo en este tema la lectura del ensayo de Jesús Rodriguez Zepeda, titulado UN MARCO
TEÓRICO PARA LA DISCRIMINACION que nos hace un repaso histórico interesantísimo sobre este
tema hasta llegar a nuestros días. El Presidente Clinton hablaba también de acción afirmativa para las
minorías étnicas, para las mujeres, para las personas con orientación sexual no convencional, y en
general a todas las personas que fueren objeto de cualquier forma de discriminación en la vida pública.
3 UNIFEM. Fondo de Desarrollo de las Naciones Unidas para la Mujer. Consultado en internet el 20 de
julio, 2009. 
igual tiende a repetir la desigualdad en todas sus instituciones, por más que la igualdad esté consagrada constitucional y legalmente. Al constatar el poco alcance de las políticas igualitarias, la mayoría de las naciones admitió que la situación de la discriminación era más compleja de lo que se pensaba, y que las medidas tendientes a lograr la igualdad social y laboral no significaban nada en si mismas, si al mismo tiempo, no se reformaba la vida familiar y se establecían condiciones de ventaja para las mujeres.

\section{NECESARIAS LA ACCIONES AFIRMATIVAS.}

Fue decisivo descubrir que no basta con declarar la igualdad de trato, cuando en la realidad no existe la igualdad de oportunidades. Esto significa, por ejemplo, que aunque la discriminación se manifiesta en el ámbito público, sus orígenes se encuentran en el ámbito privado. El diferente papel que los varones y las mujeres tienen dentro de la familia, y las consecuencias de esta asignación de papeles en el ciclo de vida, dificultan enormemente cualquier propuesta de igualdad.

En 1983, el gobierno noruego afirmó que no es posible conseguir la igualdad entre el status social del hombre y el de la mujer con sólo prohibir los tratos discriminatorios. ${ }^{4} \mathrm{Si}$ se quiere corregir la diferencia que hoy existe es necesario proporcionar ventajas en determinados campos a las mujeres.

Por eso, dentro de los programas de igualdad de oportunidades se han formulado un conjunto de medidas destinadas a corregir las diferencias de trato social entre hombres y mujeres; a estas medidas se les llamó programas de acción afirmativa o positiva.

Aunque las iniciativas de acción afirmativa se encuentran presentes en los instrumentos internacionales desde 1968, no existe consenso en torno a una definición aceptada. En 2001 las Naciones Unidas propuso una definición: "la acción afirmativa es un conjunto coherente de medidas de carácter temporal dirigidas a corregir la situación del grupo al que están destinadas en un aspecto o varios de su vida social para alcanzar la igualdad".

La ONU sostiene que la adopción de medidas especiales, de carácter temporal, encaminadas a acelerar la igualdad de hecho entre el hombre y la mujer, no se considera como un acto discriminatorio hacia el hombre.

\footnotetext{
${ }^{4}$ Segunda Directiva de Igualdad de Trato de la Comunidad Europea. Abrahamsson 2000 Suecia.
} 


\section{LA PRÁCTICA DE LA ACCIÓN AFIRMATIVA}

America Latina es una de las regiones más desiguales del mundo. Las desigualdades se expresan en participación política, acceso a educación, salud, justicia y empleo. Estas desigualdades desencadenan severos conflictos sociales y políticos. Se esperaría encontrar en estos países una prioridad para frenar estas desigualdades como son: Políticas públicas enfocadas a reducir la desigualdad, programas gubernamentales para las poblaciones mas rezagadas en desarrollo humano y esfuerzos encaminados a cambiar ideas, valores y practicas de las instituciones y ciudadanía en general a favor de la igualdad de derechos y la equidad en las oportunidades. Y aunque se han hecho esfuerzos para construir sociedades más equitativas las desigualdades no se han reducido.

En México, en 2006 se aprueba la Ley General para la Igualdad entre Mujeres y Hombres, ${ }^{5}$ cuya premisa fundamental es la ausencia de toda distinción, exclusión o restricción basada en el sexo que resulte en el menoscabo o anulación del reconocimiento, goce o ejercicio de los derechos humanos y las libertades fundamentales en las esferas política, económica, social, cultural y civil o en cualquier otra esfera.

El objetivo de la ley es garantizar la igualdad jurídica, los derechos humanos de las mujeres, la no discriminación y la aplicación de acciones afirmativas en el marco del estado de derecho a través de las siguientes líneas de acción:

1. Promover que los derechos humanos de las mujeres contenidos en los tratados y convenciones internacionales se incorporen en la legislación nacional.

2. Impulsar la armonización de la legislación en las entidades federativas conforme a las leyes generales de igualdad y de acceso de las mujeres a una vida libre de violencia, así como la homologación de los códigos penales, civiles y de procedimientos.

3. Armonizar la normatividad laboral para tutelar la no discriminación en el empleo, la igualdad de trato en la remuneración según competencias, el acceso a la protección social y a las oportunidades de ascenso, capacitación y profesionalización.

${ }^{5}$ Ley General para la Igualdad entre Mujeres y Hombres. Instituto Nacional de las Mujeres. Mexico. 2007. 
4. Establecer mecanismos para atender las denuncias de las mujeres en casos de hostigamiento sexual en el ámbito laboral, y sancionar cualquier acto que implique hostigamiento laboral por razones de edad, estado conyugal y embarazo.

5. Impulsar campañas a favor de la igualdad entre mujeres y hombres.

La ley establece la promoción de seis ejes en las políticas de igualdad entre mujeres y hombres. Considero un eje fundamental el acceso a la educación, y si bien es un instrumento clave para reducir la desigualdad social, resulta insuficiente. No puede ser la única política de igualdad o de acción afirmativa.

En algunos países, especialmente en Canadá y en los de la Comunidad Económica Europea, se han evaluado los costos económicos y sociales que habrían de pagarse si persistiera la educación sexista, que produce hombres y mujeres con actitudes disfuncionales en una sociedad que tiende a la modernidad. Si las mujeres no se educan más, si no participan de manera más activa política y laboralmente, la sociedad en su conjunto lo resentirá.

\section{CONCLUSIONES}

La acción afirmativa es una norma legal, o una política pública que pretende lograr la igualdad de oportunidades para las mujeres. En breve consiste, en escoger en una situación de paridad, a la persona que pertenezca a un sector discriminado, cualquiera que éste sea. Por tanto, requiere de un cambio de mentalidad de la sociedad en su conjunto. En México, nos encontramos trabajando en ello. Prueba de ello son las leyes expedidas recientemente, y el trabajo realizado por el Instituto Nacional de las Mujeres, que busca influir en todos los ámbitos de la sociedad mexicana.

Se debe reconocer que la desigualdad social, económica, política y educativa es un problema global que trasciende las fronteras nacionales y que por tanto requiere alianzas y respuestas globales.

Respecto de la acción afirmativa, puede estar presente en el ámbito normativo, pero no en las políticas y programas sociales. En algunos países las políticas asistenciales y los programas sociales para atender la pobreza se confunden con la acción afirmativa.

Debemos impulsar la implementación de estas acciones. En este proceso, todos somos personas clave para el desarrollo del país, por tanto, estimo que estamos en el camino correcto y por supuesto mirando hacia el futuro. 